Sharif University of Technology
Scientia Iranica
Transactions E: Industrial Engineering
IRA IENTIA $\quad$\begin{tabular}{l} 
h / scientiairanica.sharif.edu \\
\hline
\end{tabular}

\title{
Supply chain reconfiguration for new product development through risk management approach
}

\author{
M. Sabzevari ${ }^{\mathrm{a}}$, S.M. Sajadi ${ }^{\mathrm{b}, *}$, and S.M. Hadjimolana ${ }^{\mathrm{a}}$ \\ a. Department of Industrial Engineering, Science and Research Branch, Islamic Azad University, Tehran, Iran. \\ b. Faculty of Entrepreneurship, University of Tehran, Tehran, Iran.
}

Received 12 June 2018; received in revised form 29 September 2018; accepted 16 February 2019

\author{
KEYWORDS \\ Supply chain \\ reconfiguration; \\ New product \\ development; \\ Risk management; \\ Fast moving consumer \\ goods; \\ Goal programming.
}

\begin{abstract}
Nowadays, innovation is increasingly growing and the lifetime of products is decreasing. In this situation, New Product Development (NPD) is an advantage that makes it possible to survive in the competitive market. However, risks are unavoidable in NPD in any industry. Therefore, identifying, management, and mitigation of risks are considered of high significance for companies. By taking risk management into account, this study introduces a new multi-objective mathematical model for Supply Chain (SC) configuration in the presence of a new product. The considered SC is multi-echelon, multi-resource, multi-period, and multi-product. In order to manage the risk in this SC, appropriate mitigation strategies were chosen among various risk response strategies considering their cost and effectiveness. Furthermore, influence of each choice on SC was accounted for in the mathematical model. The assumed model explored the optimum tactical and operational Supply Chain Management (SCM) decisions. The ability of the model was assessed by solving a numerical example. The result showed that the choice of various response strategies as well as new product production influenced SC configuration.
\end{abstract}

(C) 2020 Sharif University of Technology. All rights reserved.

\section{Introduction}

"Supply Chain Management (SCM) aims to integrate plants with their suppliers, customers and other facilities in network so that they can be managed as a single entity, and to coordinate all input/output flows (of materials, information and funds) so that products are produced and distributed in the right quantities, to the right locations, and at the right time" [1]. Today, in a competitive industry, with the aim of gaining more

\footnotetext{
*. Corresponding author.

E-mail addresses: malihe.sabzevari@yahoo.com (M.

Sabzevari); msajadi@ut.ac.ir (S.M. Sajadi);

molana@srbiau.ac.ir (S.M. Hadjimolana)
}

competitive advantages, responsiveness is considered as a factor for differentiation [2]. It is vital for companies to consider the rapid changes in marketing situation as well as wants, likes, and needs of the consumers. There is compulsion for innovation in the market to satisfy the needs of consumers, particularly in the Fast Moving Consumer Goods (FMCG) industry. Many new products encounter challenges as they come into new markets. Studies in 2012 demonstrated that "the rate of New Product Development (NP) success was $56.8 \%$ in Europe and $48.6 \%$ in Asia" [3].

Reconfiguration of the Supply Chain (SC) is too complex, because a new product lives for a short time and further desire of the consumer is not obvious [4]. This causes some risks that are inevitable in development of new products in any industry or situation. In NPD setting, risk is the likelihood of NPD failure 


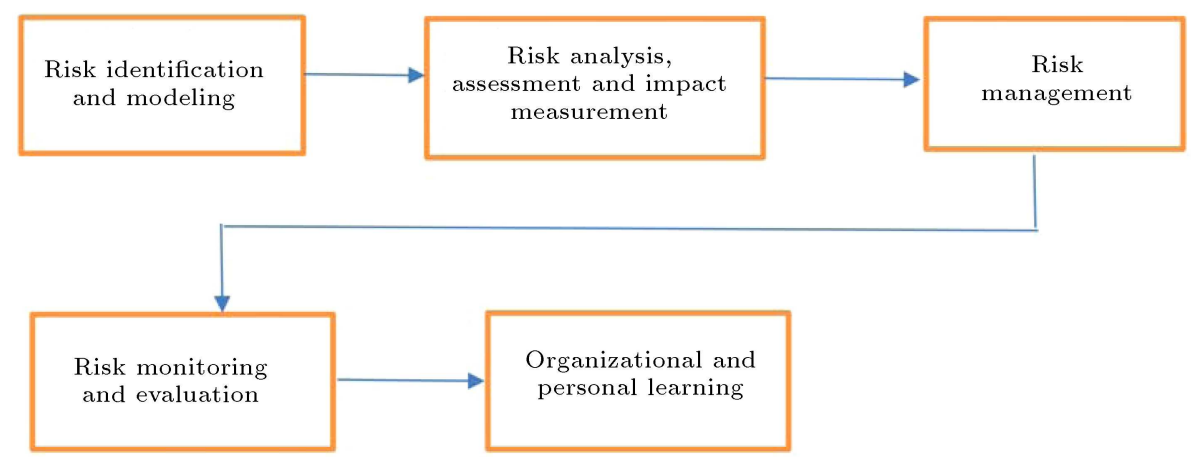

Figure 1. Suply Chain Risk Management (SCRM) activity.

because of some factors like market failure, technology restriction, and organizational obstructing factors that result in the failure of selling the new product [5]. The management of the mentioned factors is called Supply Chain Risk Management (SCRM). Definitions of SCRM basically contain the activities that are shown in Figure 1 [6].

According to Qazi et al. [7], qualitative methodology has received considerable attention in research studies, while quantitative methods have been less developed. Neither have the aspects of design change and NPD been taken into account rightly. Therefore, more studies are required to investigate the quantitative techniques. Also, it will be worthwhile if more research studies consider risks regarding NPD and explore the impact of design changes on SC risks. According to Liu and Sun (2018), when risk management is not complete, the whole construction project and operation processes may face a large number of problems [8].

This study aims to develop an approach for configuring a multi-echelon, multi-product, and multiperiod SC for a new product considering economic performance and quantitative risk aspects with the goal of increasing satisfaction level of consumers. Net Present Value (NPV), risk, and consumer satisfaction level have been considered as the three objectives of $\mathrm{SC}$ in a deterministic multi-objective optimization model. This study aims to identify the most efficient strategies in order to mitigate the risks. To maintain the efficiency and effectiveness, decisions regarding the selection of the plant that will manufacture the new product, the suppliers, and the distribution centers which will sell it should be made prior to launching a new product.

The rest of the paper is organized as follows. Section 2 provides a review of the literature on the related research topics and methods. Section 3 presents the proposed model of SC configuration. Numerical data and statistics as well as the results of the performance and risk assessment are given in Section 4. The sensitivity of financial parameters is assessed in Section 5 .
Finally, the paper ends with a discussion and concluding remarks in Section 6 .

\section{Literature review}

\subsection{NPD and $S C$ configuration}

Early research on new product and technology diffusion in the marketing literature can be traced back to the 1960s [9]. The need to study this area is essential because, according to Amini and Li [10], successful launch of new products raises the general profit of a company by an average of $31 \%$.

Amini and $\mathrm{Li}$ [10] developed an integrated optimization model with the purpose of configuration of $\mathrm{SC}$ subject to demand dynamics and other SC parameters. In the integrated model introduced by $\mathrm{Li}$ and Amini [11], decisions are made to determine multiple-sourcing and safety stock placement in the line in the new product diffusion processes as demand dynamics over its life cycle. Gaur et al. [12] studied a Closed Loop Supply Chain Configuration (CLSCC) for new product and its reconditioned version. The mixedinteger nonlinear programming model they offered could concurrently determine optimal production/sales plan and configure the whole CLSC. In another study, Nepal et al. [13] enhanced SC efficiency and stability by a model that cooperatively incorporated sourcing, inventory costs, and compatibility decisions in the configuration of the SC.

Jafarion and Bashiri [14] presented a dynamic SC model which accounted for the time of new product launching in the $\mathrm{SC}$ and concurrently optimized it with $\mathrm{SC}$ configuration. Their model also took production, sales, transportation planning, and their lead times into consideration.

Afrouzy et al. [15] developed an SC model that integrated development of product, production of old and new products, and their impact on SC configuration. In another study, they [16] improved their model by assuming stochastic parameters related to demands and capacities of suppliers.

Brandenburg [17] employed a goal programming 
approach considering economic and environmental criteria. The performance of the approach was demonstrated by the case example of an FMCG manufacture. In this study, a scenario approach also modeled the effect of long-term demand uncertainties.

Brandenburg [4] proposed a hybrid approach in order to configure an eco-efficient SC for a new product. This paper utilized a discrete-event simulation to evaluate the financial, operational, and environmental performance of varying SC configuration options while the Value-At-Risk (VAR) concept was adopted to assess the associated SC risks.

Graves and Willems [18] investigated the ways of configuring the SC for a new product that had been designed before. They contended that the suppliers, parts, processes, and transportation modes should be specified at each step in the SC.

Chauhan et al. [19] explored the issue of SC design strategically when the opportunity for a new market production/distribution needed to be launched in an existing SC. A deterministic Mixed-Integer Linear Programming (MILP) model was employed for a multiechelon SC. Jahani et al. [20] reconfigured an existing supply change network structure in which new products were launched to the market. They also considered correlation between demand and price in the markets. Table 1 shows the related studies to clarify the main contributions of the present study to the formulated structure.

\subsection{Supply Chain Risk Management (SCRM)}

SCRM has received remarkable attention in recent years, because the risk events that influence an SC have increased [6]. In this section, we refer to some related studies about this area.

Brandenburg [4] accounted for the VAR concept to suggest a green supply chain design and assess the associated SC risks. He proposed a simulation model for two kinds of SC configuration options. The requirement of establishing robust and resilient supply networks was highlighted by Klibi et al. [21]. They stated that cash flow should be reduced during a multiperiod planning horizon as a metric, which indicated $\mathrm{SC}$ uncertainties.

Kayis et al. [22] suggested a new method in the engineering projects that simultaneously mitigated risk in the process of design and development of new product. First, they prioritized and quantified the risks and then, they used five computational algorithms for mitigating those risks.

More evaluations related to the issue are provided in review articles. We refer to some of them here. Tang and Musa [23] reviewed various quantitative models for managing SC risks. Different SCRM strategies were connected to the actual practices. They found that those quantitative models were primarily designed for managing operational risks rather than disruption ones. Prakash et al. [24] devised a systematic literature review approach. They suggested a change of focus toward establishing and verifying SCRM theories employing techniques like hypothesis testing, simulations, surveys, case studies, etc. The literature arrangement of Peidro et al. [25] centered on a taxonomy in three dimensions: sources of uncertainty, problem type, and modelling approach. Three sources of demand, process/manufacturing, and supply uncertainty were recognized for uncertainty. Khojasteh-Ghamari and Irohara [26], after exploring SCRM papers of three previous years, observed that companies were making effort to manage $\mathrm{SC}$ risk while minimizing cost and maximizing profit and NPV. Risk could be on supply side, demand side, or process side. They believed that researchers would be interested in stochastic methods for SCRM over time. Sahling and Kayser [27] paid attention to vendor selection in context for supply network planning to develop a non-linear model approximated by an MILP.

In the model developed by Guillén et al. [28], multi-objective stochastic programming was utilized to specify the optimal retrofit of the existing SC. A robust multi-objective SC design model was proposed and evaluated by a case example from food industry by Azaron et al. [29]. Nickel et al. [30] suggested an MILP model for multi-period network design. The decisions that needed to be made were related to facility location, material flow, and fixed asset investments. By taking efficiency and risk into account, Huang et al. [31] presented a branch-and-reduce algorithm to specify Pareto-optimal robust supply network configurations.

Most studies concerned with SC redesign or configuration only consider financial risks without paying attention to other significant strategic risks, such as operational and sustainability, which were suggested by Heckmann et al. [32] and Fahimnia et al. [33]. Therefore, there is a need to consider different types of risk and the appropriate response strategies against them. Also, the impact of these mitigating strategies on the configuration of $\mathrm{SC}$ in the presence of a new product is worthy of attention.

\subsection{Research motivation}

To improve NPD activities in an SC, this study presents an MILP model that accounts for a multi-echelon, multi-product, multi-period, and multi-source $\mathrm{SC}$ with NPD and the risk related to it. The previously conducted research studies are generalized in the following aspects:

- The remarkable risks associated with developing new or old products in an FMCG supply chain as well as different risk response strategies for each risk are considered. The proposed model aims at finding the most efficient response for each risk; 
Table 1. New Product Development (NPD) and Supply Chain (SC) configurations.

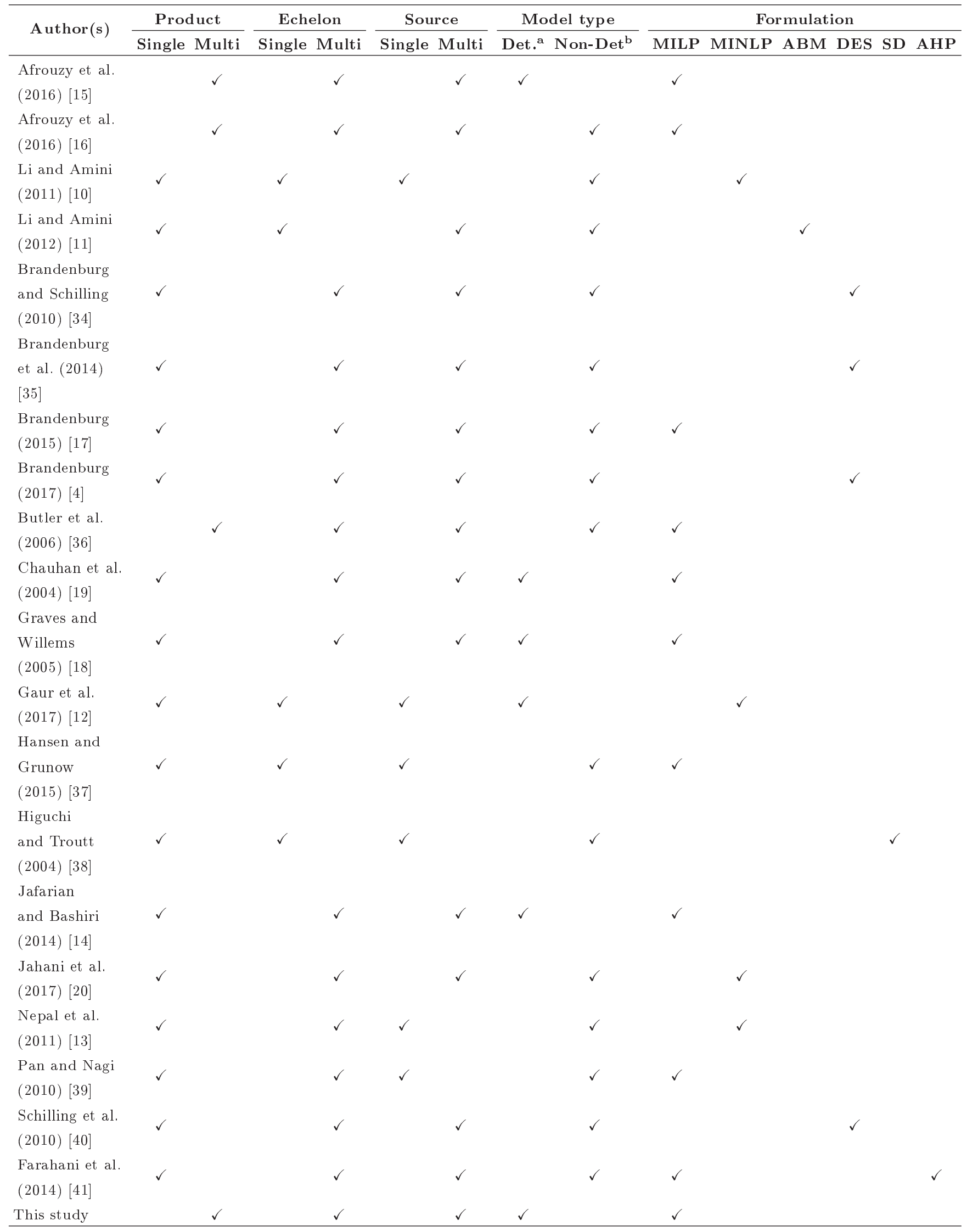

${ }^{\mathrm{a}}$ Det.: Deterministic; ${ }^{\mathrm{b}}$ Non-Det.: Non-Deterministic. 
- The effects of each risk response strategy on improving the level of demand, final production, and raw material supply capacity are considered in the model.

\section{Problem description}

Risk factors as well as their probability and effects need to be identified. Identifying potential risks can rest on the knowledge of experts, historical information, and SC structure [5]. The cost of risk response and risk reduction/elimination stand against each other. The higher the commitment to risk reduction gets, the further the cost of response strategies inflates. The proposed framework pays attention to optimizing cost as well as risk and customer satisfaction level. To identify the optimal response strategies for each risk, an optimization model is formulated. Each plant is capable of designing and introducing the new product in the planning horizon. Since risks are capable of being correlated, the model guarantees that mitigating the risk in one part of the $\mathrm{SC}$ will not results in increasing the risk in another part. The model gives a quantitative risk analysis to help companies in making decisions on how to allocate limited resources to the risks. To support these decisions, the SC configuration problem is formulated as an MILP optimization model.

\section{Assumptions}

- A three-echelon SC model, which consists of several suppliers, manufacturers, and distributors, is considered and several products are produced;

- The new product is manufactured from some new raw materials using the available systems;

- Producers have two kinds of inventories, namely inventory of raw material and inventory of final product. Inventory can decrease idleness, especially in demand fluctuation circumstances during the product life cycle;

- Limitations related to a fixed order quantity and a daily production capacity cause minimum and maximum lot sizes;

- Supplier and production plants are expected to work under a push strategy;

- The SC works undergoing a make-to-stock policy that rests on estimated demands;

- Demand is supposed to be deterministic for three periods;

- Market demands of wholesalers, distributors, and retailers are met right from stock by the distribution centers;
- If the demand cannot be satisfied fully and in time, backorders are not permitted; hence, the sales are lost.

The indices, sets, and parameters that are designed to model the SC network are defined in the following figure. We continue with a brief description of the objective function and constraints of the model.

\subsection{Model formulation}

The structure of the aforementioned $\mathrm{SC}$ is depicted in Figure 2. It includes the following elements:

- A set of suppliers that send raw materials to plants;

- A set of plants that produce products. There are warehouses for storing raw materials in addition to final products before and after production;

- A set of final markets that make products accessible to customers. There are warehouses for final products too.

The overall problem can be formally expressed as follows:

\section{Indexing sets}

$t \quad$ Index of periods

$s \quad$ Index of suppliers

$l \quad$ Index of manufacturers (set $L$ )

$r \quad$ Index of demand regions (set $R$ )

$k \quad$ Index of raw materials

$p \quad$ Index of finished products

$\vartheta \quad$ Set of transportation connections

$x \quad$ Set of plant and demand region locations

$i \quad$ Set of items $k, p$

$w \quad$ Index of risks

$q \quad$ Index of response strategies

$\delta_{\theta} \quad$ Duration of transport via connection $\theta \in \vartheta$

\section{Scalars}

$B \quad$ Dedicated budget to risk response

$\pi^{\text {cap }} \quad$ Cost of capital

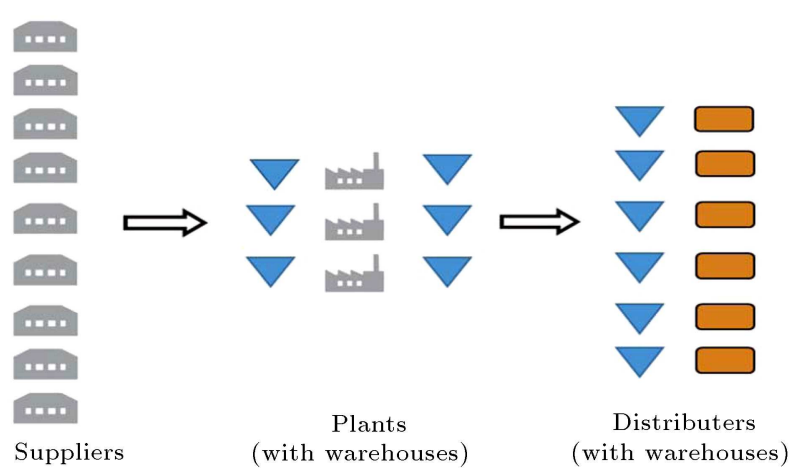

Figure 2. Supply Chain (SC) structure. 


\section{Parameters}

Parameters related to risk:

$R_{w q}^{\prime} \quad$ Amount of reduction in risk $w$ after implementing response strategy $q$

$R_{w} \quad$ Level of risk $w$ before implementing response strategy

$R_{w}^{*} \quad$ Target value of risk $w$

Prices and costs:

$\pi_{p, r}^{\text {sell }} \quad$ Selling price of finished product $p$ in demand region $r$

$\pi_{i, x}^{\text {store }} \quad$ Storage cost per unit of item $i$ at location $x$

$\pi_{s, l}^{\text {trans }} \quad$ Cost of transportation connection from supplier $s$ to plant $l$

$\pi_{l, r}^{\text {trans }} \quad$ Cost of transportation connection from plant $l$ to demand region $r$

$\pi_{k, s}^{\text {raw }} \quad$ Cost of raw material $k$ that is supplied by supplier $s$

$\pi_{p, l}^{c o n v} \quad$ Cost of conversion in production $p$ at plant $l$

$c_{q} \quad$ Cost of strategy implementation $q$

Capacities:

$\mu_{k, s}^{\text {raw }} \quad$ Minimum order quantity of raw material $k$ from raw supplier $s$

$c a p_{k, s}^{r a w} \quad$ Production capacity of raw material $k$ from raw supplier $s$

$\mu_{p, l}^{c o n v} \quad$ Minimum production of finished product $p$ at plant $l$

$\operatorname{cap}_{p, l}^{c o n v} \quad$ Production capacity of finished product $p$ at plant $l$

Impact of implementing risk response strategies:

$\Delta_{q, k, s}^{r a w} \quad$ Deviation of production capacity of raw material $k$ from raw supplier $s$ by using strategy $q$

$\Delta_{q, p, l}^{c o n v} \quad$ Deviation of production capacity of finished product $p$ at plant $l$ by using strategy $q$

$\Delta_{q, p, r, t}^{\text {demand }} \quad$ Deviation of demand of finished product $p$ at demand region $r$ in period $t$ by using strategy $q$

Demand:

$d_{p, r, t} \quad$ Demand of finished product $p$ at demand region $r$ in period $t$

Transportation connection:

$\theta_{s, l} \quad$ Binary parameter for transportation connection from supplier $s$ to plant $l$

$\theta_{l, r} \quad$ Binary parameter for transportation connection from plant $l$ to demand region $r$

\section{Bill of material:}

$\varphi_{k, p} \quad$ Quantity of raw material $k$ used for producing finished product $p$

\section{List of variables}

Positive variables:

$x y_{q, s, t}^{\text {raw }} \quad$ Auxiliary variable for linearized product of $x_{q}$ and $y_{s, t}^{\text {raw }}$

$x y_{q, p, l}^{c o n v} \quad$ Auxiliary variable for linearized product of $x_{q}$ and $y_{p, l}^{c o n v}$

\section{Cost variables:}

$c f_{t} \quad$ Cash flow in period $t \in T$

$c i_{t} \quad$ Cash inflow in period $t \in T$

$\mathrm{co}_{t} \quad$ Cash outlay in period $t \in T$

$c_{t}^{\text {store }} \quad$ Total storage cost in period $t \in T$

$c_{t}^{\text {trans }}$ Total transportation cost in period $t \in T$

$c_{t}^{\text {raw }} \quad$ Total cost of raw material in period $t \in T$

$c_{t}^{\text {conv }} \quad$ Total conversion cost in period $t \in T$

$c_{t}^{\text {risk }} \quad$ Total risk cost in period $t \in T$

Decision variables:

$q_{p, r, t}^{\text {sale }} \quad$ Sale quantity of finished product $p$ at demand region $r$ in period $t \in T$

$q_{i, x, t}^{\text {store }} \quad$ Storage quantity of item $i \in\{k, p\}$ at location $x \in L \cup R$ in period $t \in T$

$q_{k,(s, l), t}^{\text {trans }} \quad$ Transportation quantity of raw material $k$ on transportation connection from supplier $s$ to plant $l$ in period $t \in T$

$q_{p,(l, r), t}^{\text {trans }} \quad$ Transportation quantity of finished product $p$ on transportation connection from plant $l$ to demand region $r$ in period $t \in T$

$q_{k, s, t}^{\text {raw }} \quad$ Raw material quantity of material $k$ supplied by supplier $s$ in period $t \in T$

$q_{p, l, t}^{c o n v} \quad$ Production quantity of finished product $p$ at plant $l \in L$ in period $t \in T$

$q_{p, r, t}^{\text {lost }} \quad$ Quantity of lost order of finished product $p$ in demand region $r \in R$ and period $t \in T$ 
Binary decision variables:

$x_{q}=\left\{\begin{array}{ll}1 & \text { if response strategy } q \text { is selected } \\ 0 & \text { otherwise }\end{array}\right\}$,

$y_{s, t}^{\text {raw }}=\left\{\begin{array}{ll}1 & \text { if supplier } s \text { worked at period } t \in T \\ 0 & \text { otherwise }\end{array}\right\}$,

$y_{p, l}^{c o n v}=\left\{\begin{array}{ll}1 & \text { if finished product } p \text { produced by } \\ \text { plant } l \text { in period } t \in T \\ 0 & \text { otherwise }\end{array}\right\}$.

\section{Objective functions}

The economic objective of company value is to maximize the $N P V$, i.e. the discounted sum of cash flows from the resulting SC configuration and operation decisions.

$$
\max \quad N P V=\sum_{t \in T} \frac{c f_{t}}{\left(1+\pi^{c a p}\right)^{t-1}} .
$$

The objective function related to customer satisfaction level, given with the minimum Lost Income (LI), is as follows:

$$
\min \quad L I=\sum_{p \in P} \sum_{r \in R} \sum_{t \in T} \pi_{p, r}^{\text {sell }} q_{p, r, t}^{\text {lost }} .
$$

Risk objective function maximizes total risk reduction.

$$
\max \operatorname{risk}\left(\text { reduction) }=\sum_{w=1}^{W} \sum_{q=1}^{Q}\left(\frac{R_{w q}^{\prime} x_{q}}{R_{w}}\right) .\right.
$$

\section{Constraints}

Financial constraints

Cash flows caused by SC configuration and operation are taken into account by financial restrictions. The cash flow of period $t \in T$ is calculated by the difference of cash inflow $c i_{t}$ and cash outlay $c_{t}$ (Constraint (4)). The amount of total product sales determines cash inflow $c i_{t}$ for each period $t \in T$ (Constraint (5)). The amount of the entire cost of storage, transportation, raw materials, finished goods production, and risks presents cash outlay for each period (Constraint (6)).

$$
\begin{array}{ll}
c f_{t}=c i_{t}-c o_{t} & \forall t \in T, \\
c i_{t}=\sum_{p \in P} \sum_{r \in R} \pi_{p, r}^{\text {sell }} q_{p, r, t}^{\text {sales }} & \forall t \in T, \\
c o_{t}=c_{t}^{\text {store }}+c_{t}^{\text {trans }}+c_{t}^{\text {raw }}+c_{t}^{\text {conv }}+c_{t}^{\text {risk }} & \forall t \in T .
\end{array}
$$

\section{Cost constraints}

By further constraints, the costs of storage (Constraint (7)), transportation (Constraint (8)), raw material (Constraint (9)), conversion of finished goods production (Constraint (10)), and mitigating the risks (Constraint (11)) will be calculated more precisely. The sum of the selected risk response strategies is divided by 365 as we choose it once a year, unlike the other costs that are chosen every day.

$$
\begin{array}{rlrl}
c_{t}^{\text {store }}=\sum_{i \in\{k . p\}} \sum_{x \in L \cup R} \pi_{i . x}^{\text {store }} \cdot q_{i . x . t}^{\text {store }} & & \forall t \in T, \\
c_{t}^{\text {trans }}=\sum_{i \in\{k . p\}} \sum_{\theta \in \vartheta} \pi_{\theta}^{\text {trans }} q_{i . \theta . t}^{\text {trans }} & \forall t \in T, \\
c_{t}^{\text {raw }}=\sum_{k \in K} \sum_{s \in S} \pi_{k, s}^{\text {raw }} q_{k, s, t}^{\text {raw }} & \forall t \in T, \\
c_{t}^{\text {conv }}=\sum_{p \in P} \sum_{l \in L} \pi_{p, l}^{\text {conv }} q_{p, l . t}^{\text {conv }} & \forall t \in T, \\
c_{t}^{\text {risk }}=\sum_{q}\left(x_{q} c_{q}\right) / 365 & \forall t \in T .
\end{array}
$$

\section{Capacity constraints}

Minimum lot sizes are represented by operational constraints on the supply side and plant production (Constraint (12) and (14)). It is possible to increase maximum capacities of suppliers and the production factories. This change can occur by selecting risk response strategies associated with capacities, e.g. interplant inventory sharing, on-site supplier hubs, redundant suppliers, etc. (Constraint (13) and (15)). This model is nonlinear due to Constraints (13) and (15).

$$
\begin{aligned}
& \mu_{k, s}^{r a w} \cdot y_{s, t} \leq q_{k, s, t}^{r a w} \quad \forall t \in T, \quad s \in S, \quad k \in K, \\
& q_{k, s, t}^{r a w} \leq C A P_{k, s}^{r a w} \cdot y_{s, t}^{r a w}+\sum_{q} \Delta_{q, k, s}^{r a w} \cdot x_{q} \cdot y_{s, t}^{r a w} \\
& \forall t \in T, \quad s \in S, \quad k \in K, \\
& \mu_{p, l}^{c o n v} \cdot y_{p, l}^{c o n v} \leq q_{p, l . t}^{c o n v} \quad \forall p \in P, \quad l \in L, \quad t \in T, \\
& q_{p, l . t}^{\text {conv }} \leq C A P_{p, l}^{c o n v} \cdot y_{p, l}^{c o n v}+\sum_{q} \Delta_{q, p, l}^{c o n v} \cdot x_{q} \cdot y_{p, l}^{c o n v} \\
& \forall t \in T, \quad l \in L, \quad p \in P .
\end{aligned}
$$

\section{Transportation constraints}

Operational constraints for the material flow assure that supplier and production plants utilize a push strategy, i.e. produced quantities are shipped from the supplier (Constraint (16)) or production plant (Constraint (17)) to the receiver of goods after production has finished. In this model, the finished products can also be stored in plants for a period of time. Besides, mass balances are applied to finished goods 
(Constraint (18)) and components (Constraint (19)).

$$
\begin{aligned}
q_{k, s, t}^{\text {raw }} & =\sum_{l \in L} \sum_{(s, l) \in \vartheta} q_{k,(s, l), t}^{\text {trans }} \\
\forall k & \in K, \quad s \in S, \quad t \in T \\
q_{p, l, t}^{\text {store }} & =q_{p, l, t-1}^{\text {store }}+q_{p, l, t}^{\text {conv }}-\sum_{r \in R} \sum_{(l, r) \in \vartheta} q_{p,(l, r), t}^{\text {trans }}, \\
\forall l & \in L, \quad p \in P, \quad t \in T \\
q_{p, r, t}^{\text {store }} & =q_{p, r . t-1}^{\text {store }}-q_{p, r, t}^{\text {sales }}+\sum_{l \in L} \sum_{\theta \in \vartheta} q_{p, \theta, t-\delta_{\theta}}^{\text {trans }} \\
\forall p & \in P, \quad r \in R, \quad t \in T, \\
q_{k, l, t}^{\text {store }} & =q_{k, l, t-1}^{\text {store }}-\sum_{p \in P} \varphi_{k, p} . q_{p, l, t}^{\text {conv }}+\sum_{s \in S} \sum_{\theta \in \vartheta} q_{k, \theta, t-\delta_{\theta}}^{\text {trans }} \\
\forall t & \in T, \quad l \in L, \quad k \in K .
\end{aligned}
$$

\section{Demand}

Backorders are not permitted and demands that are not fully satisfied result in lost sales. Therefore, operational constraints on the demand side indicate sales and lost sales quantities that must match the demands (Constraint (20)). If some risk response strategies that are related to the marketing risk, e.g., proactive market orientation, branding, lean production, etc., are applied, demands can rise. The impact of these strategies is shown in demand constraint.

$$
\begin{gathered}
q_{p, r, t}^{\text {sales }}+q_{p, r . t}^{\text {lost }}=d_{p, r, t}+\sum_{q} \Delta_{q, p, r, t}^{\text {demand }} \cdot x_{q} \\
\forall p \in p, \quad r \in R, \quad t \in T .
\end{gathered}
$$

\section{Budget}

This constraint ensures that the total cost for mitigating the risk will not be more than the assigned budget.

$$
\sum_{q} x_{q} c_{q} \leq B
$$

\section{Target level of the risk}

The resulting risk value must be less than or equal to the target level of that risk after implementing the mitigation strategies (Constraint (22)). Constraint (23) shows that the total reduction in the risk level must be greater than or equal to zero:

$$
\begin{aligned}
& R_{w}-\sum_{q \in Q}\left(R_{w q}^{\prime} \cdot x_{q}\right) \leq R_{w}^{*}, \\
& \sum_{q \in Q} R_{w q}^{\prime} \cdot x_{q} \geq 0 .
\end{aligned}
$$

\section{Problem simplification}

By introducing the auxiliary variables $x y(q, s, t)^{\text {raw }}$ and $\left.x y_{(} q, p, l\right)^{\text {conv }}$, Constraints (13) and (15), which are nonlinear, can be transformed into the following equivalent programming problem.

Constraint (13):

$$
\begin{gathered}
q_{k, s, t}^{r a w} \leq C A P_{k, s}^{r a w} \cdot y_{s, t}^{r a w}+\sum_{q} \Delta_{q, k, s}^{r a w} \cdot x y_{q, s, t}^{r a w} \\
\forall t \in T, \quad s \in S, \quad k \in K
\end{gathered}
$$

is equivalent to:

$$
\begin{array}{ll}
x y_{q, s, t}^{\text {raw }} \geq x_{q}+y_{s, t}^{\text {raw }}-1 & \forall q \in Q, \quad s \in S, \quad t \in T, \\
x y_{q, s, t}^{\text {raw }} \leq x_{q} & \forall q \in Q, \quad s \in S, \quad t \in T, \\
x y_{q, s, t}^{\text {raw }} \leq y_{s, t}^{\text {raw }} & \forall q \in Q, \quad s \in S, \quad t \in T .
\end{array}
$$

Constraint (15):

$$
\begin{gathered}
q_{p, l . t}^{c o n v} \leq C A P_{p, l}^{c o n v} \cdot y_{p, l}^{c o n v}+\sum_{q} \Delta_{q, p, l}^{c o n v} \cdot x y_{q, p, l}^{c o n v} \\
\forall l \in L, \quad p \in P, \quad t \in T
\end{gathered}
$$

is equivalent to:

$$
\begin{array}{lll}
x y_{q, p, l}^{\text {conv }} \geq x_{q}+y_{p, l}^{\text {conv }}-1 & \forall q \in Q, & p \in P, \quad l \in L, \\
x y_{q, p, l}^{\text {conv }} \leq x_{q} & \forall q \in Q, & p \in P, \quad l \in L, \\
x y_{q, p, l}^{\text {conv }} \leq y_{p, l}^{\text {conv }} & \forall q \in Q, & p \in P, \quad l \in L .
\end{array}
$$

\section{Solution approach}

The optimization model is formulated and solved by employing weighted global criterion method. This method replaces multiple objectives with a single objective by which the distance between each objective and its ideal amount is minimized. Weights $\left(w_{N P D}\right.$, $\left.w_{\text {risk }}, w_{L S}\right)$ are used to indicate the three objectives with different degrees of significance. The optimization problem is formulated as follows:

$$
\begin{aligned}
\max \quad z= & w_{N P D} \cdot \frac{N P V-N P V^{\min }}{N P V^{\max }-N P V^{\min }} \\
& +w_{r i s k} \cdot \frac{r i s k-r i s k^{\min }}{r i s k^{\max }-r i s k^{\min }} \\
& +w_{S L} \cdot \frac{L I^{\max }-L I}{L I^{\max }-L I^{\min }} .
\end{aligned}
$$

$X^{\min }$ and $X^{\max }, X \in\{N P V$, Risk, $L I\}$, represent the minimum and maximum quantities of $X$ in payoff matrix. Payoff matrix is an $n \times n$ matrix in which element $(i, j)$ shows the quantity of objective function $j$ by optimizing the objective function $i$. 
Table 2. Risks and related risk response strategies.

\begin{tabular}{|c|c|}
\hline Risk & Risk responds strategies \\
\hline 1. Customers' acceptance & $\begin{array}{l}\text { 1. Proper understanding of customers' behaviors and needs; } \\
\text { 2. Choosing correct marketing strategies (organized marketing channel); } \\
\text { 3. Proactive market orientation; } \\
\text { 4. Branding; } \\
\text { 5. Giving explanation to customers (special explanation about what } \\
\text { makes the product different from the previous ones and why they } \\
\text { should buy it); } \\
\text { 6. Advertising. }\end{array}$ \\
\hline 2. Competitors & $\begin{array}{l}\text { 1. Reducing the prime cost of product; } \\
\text { 2. Lean manufacturing; } \\
\text { 3. Using sales offer. }\end{array}$ \\
\hline
\end{tabular}

Wrong estimation of sales quantity

3. as well as production cost in future, price elasticity, and price

4. Problems of electricity distribution

1. Purchasing a power generator.

5. Problems of suppliers

1. Supervising suppliers;

2. Enhancing suppliers' knowledge;

3. Redundant supplier;

4. Interplant inventory sharing.

6. Order cancellation

1. Searching for new customers for each period (for every one percent of order cancellation in each period, one percent new distributor should be found each month).

1. APQA;

7. Quality problems

2. More experiments (proper control of incoming items and suitable structure design in laboratory);

3. ISO.

1. Insurance;

8. Natural disasters

2. Retrofitting the buildings;

3. Adding equipment,

\subsection{Experimental study}

To show performance efficiency of the proposed model, in this section, a hypothetical numerical example is illustrated. Consider a three-echelon SC operating in the beverage sector including six raw material suppliers, three plants, and nine distribution centers, which produces three products by using four raw materials. A new product will be developed by using existing facilities. First, NPD risks in an SC should be identified, measured, and prioritized. The risk response strategies for each risk should also be identified. The probabilities of the risk events and their impacts as well as the amounts of risk reduction after implementing risk response strategies need to be scored by knowledge of the experts. Some of the risks related to NPD in an FMCG supply chain are listed in Table 2.

It is assumed that demands for products are deterministic and have been made individually for three 
Table 3. Parameters and intervals for their random values.

\begin{tabular}{lccccccc}
\hline Parameter & $\pi_{s, l}^{\text {trans }}, \pi_{l, r}^{\text {trans }}$ & $\varphi_{k, p}$ & $\pi_{i, x}^{\text {raw }}$ & $\pi_{i, x}^{\text {store }}$ & cap $_{k, s}^{\text {raw }}$ & $\operatorname{cap}_{p, l}^{\text {conv }}$ & $\mu_{k, s}^{\text {raw }}$ \\
Range of values & $(0.1,0.2)$ & $(0,0.9)$ & $(0,3.2)$ & $(0,0.25)$ & $(0,500000)$ & $(15000,150000)$ & $(0,100000)$ \\
Parameter & $\mu_{p, l}^{\text {conv }}$ & $\pi_{p, l}^{\text {sell }}$ & $\pi_{p, l}^{\text {conv }}$ & $R_{w q}^{\prime}$ & $R_{w}$ & $\Delta_{q, k, s}^{\text {raw }}$ & $\Delta_{q, p, l}^{\text {conv }}$ \\
Range of values & $(3000,200000)$ & $(4.45,10.6)$ & $(0.19,2.2)$ & $(0,0.06)$ & $(0.25,0.33)$ & $(0,25000)$ & $(0,1000)$ \\
\hline
\end{tabular}

Table 4. Risk-related model input and interest rate.

\begin{tabular}{clc}
\hline $\begin{array}{c}\text { Input } \\
\text { variable }\end{array}$ & \multicolumn{1}{c}{ Variable name } & value \\
\hline$W$ & Number of risks & 10 \\
$Q$ & Number of response strategies & 20 \\
$B$ & Total available budget & $\$ 3,000,000$ \\
$R_{w}^{*}$ & Target value of risk $w$ & 0.199 \\
$\pi^{c a p}$ & Cost of capital & 0.2 \\
\hline
\end{tabular}

Table 5. Total cost in each period.

\begin{tabular}{clccc}
\hline & Variable name & $\boldsymbol{t}_{\boldsymbol{1}}$ & $\boldsymbol{t}_{\boldsymbol{2}}$ & $\boldsymbol{t}_{\mathbf{3}}$ \\
\hline $\boldsymbol{c} \boldsymbol{f}_{\boldsymbol{t}}$ & Cash flow & 3096105 & 3189167 & 3201297 \\
$\boldsymbol{c i}_{\boldsymbol{t}}$ & Cash inflow & 4378791 & 4425031 & 4390388 \\
\hline
\end{tabular}

periods. For parameters, random values are generated in given intervals. Table 3 shows the parameters and their random values.

Parameter $\Delta_{q, p, r, t}^{\text {demand }}$ shows the amount of increase in finished products sale caused by employing response strategies. It is assumed that this amount of increase is $10 \%$. Strategies that affect sales are Strategies 1-10 and Strategy 15. Table 4 shows the rest of input data.

\subsection{Results}

This example has been solved by GAMS software. In Tables 5-15, optimal configurations of the proposed model are depicted for the considered example. Table 5 demonstrates cost variables. Table 6 refers to decision variables on sales quantity of the finished product in the sales centers.

Table 7 shows the appropriate storage quantity of finished product in plants and sale centers. The variable of decision on transportation is illustrated in Table 8.

Optimal raw material transportation quantity from suppliers to plants is given in Table 9 . Table 10 presents raw material quantity supplied by each supplier and the optimal production of finished product quantity in each plant.

Table 11 represents the lost sale quantity of the
Table 6. Sales quantity of finished product.

\begin{tabular}{|c|c|c|c|c|}
\hline $\boldsymbol{q}_{p, r, t}^{\text {sale }}$ & & & & \\
\hline $\begin{array}{l}\text { Finished } \\
\text { product }\end{array}$ & & $t_{1}$ & $t_{2}$ & $t_{3}$ \\
\hline \multirow{6}{*}{$p_{1}$} & $r_{1}$ & 7290.00 & 7790 & 6790 \\
\hline & $r_{2}$ & 31350 & 32350 & 30350 \\
\hline & $r_{3}$ & 41820 & 41820 & 42820.00 \\
\hline & $r_{4}$ & 104250 & 114250 & 1042.50 \\
\hline & $r_{5}$ & 20685.00 & 19685 & 21685.00 \\
\hline & $r_{6}$ & 52260 & 50260 & 53260 \\
\hline \multirow{6}{*}{$p_{2}$} & $r_{1}$ & 5220 & 6220 & 5720.00 \\
\hline & $r_{2}$ & 6455.333333 & 9440 & 10440.00 \\
\hline & $r_{3}$ & 26649.67 & 11910 & 0.00 \\
\hline & $r_{4}$ & 0 & 5000 & 16610 \\
\hline & $r_{5}$ & 5175 & 5675 & 5275 \\
\hline & $r_{6}$ & 0 & 5255 & 5455 \\
\hline \multirow{6}{*}{$p_{3}$} & $r_{1}$ & 3135.00 & 2635 & 3235 \\
\hline & $r_{2}$ & 12450 & 12450 & 11950 \\
\hline & $r_{3}$ & 31200.00 & 31200 & 31400 \\
\hline & $r_{4}$ & 72900.00 & 73900 & 71900 \\
\hline & $r_{5}$ & 5190.00 & 4690 & 5290 \\
\hline & $r_{6}$ & 6222 & 5722 & 5922 \\
\hline \multirow{6}{*}{$p_{4}$} & $r_{1}$ & 1041 & 891 & 941 \\
\hline & $r_{2}$ & 5235 & 4735 & 5835 \\
\hline & $r_{3}$ & 4170 & 4270 & 4370 \\
\hline & $r_{4}$ & 10440 & 10940 & 12440 \\
\hline & $r_{5}$ & 2091 & 1591 & 1791 \\
\hline & $r_{6}$ & 5235 & 5735 & 5335 \\
\hline
\end{tabular}

finished product. To make it short, the variables not listed in the table have the value of zero.

\subsection{Binary decision variables}

After the model was run, all risk response strategies 
Table 7. Storage quantity of raw material and products in different place and time.

\begin{tabular}{ccccc}
\hline \multicolumn{1}{c}{$\boldsymbol{q}_{\boldsymbol{i}, \boldsymbol{x}, \boldsymbol{t}}^{\text {store }}$} & $\boldsymbol{t}_{\mathbf{1}}$ & $\boldsymbol{t}_{\mathbf{2}}$ & $\boldsymbol{t}_{\mathbf{3}}$ \\
\cline { 1 - 5 } $\begin{array}{c}\text { Raw material } \boldsymbol{k} \text { and } \\
\text { finished product } \boldsymbol{p}\end{array}$ & $\begin{array}{c}\text { Manufacturer } \boldsymbol{l} \\
\text { and distributer } \boldsymbol{r}\end{array}$ & & & \\
\cline { 1 - 3 }$k_{1}$ & $l_{1}$ & 0 & 0 & 86464.3 \\
$k_{2}$ & $l_{1}$ & 0 & 0 & 583.50 \\
$k_{2}$ & $l_{2}$ & 1570.50 & 0 & 970.50 \\
$k_{2}$ & $l_{3}$ & 1817.2 & 0 & 1517.2 \\
$k_{3}$ & $l_{2}$ & & 0 & 24369.10 \\
$k_{3}$ & $l_{3}$ & 25830.70 & 0 & 0 \\
$p_{1}$ & $r_{2}$ & 32350 & 0 & 0 \\
$p_{1}$ & $r_{3}$ & 0 & 0 & 42820 \\
$p_{1}$ & $r_{4}$ & 0 & 0 & 104250 \\
\hline
\end{tabular}

were selected except for strategies number $4,6,7,9$, 15 , and 16 .

The results show that except for product 2 , all the other products are produced in plant 1 and in selecting the suppliers, suppliers 1 and 4 in the first period; suppliers 1 and 5 in the second period; and suppliers 1 , 4 , and 5 in the third period have not been chosen.

Table 12 presents optimal values of objective functions and their weights.

\section{Sensitivity analysis}

To show the performance of the proposed model, a sensitivity analysis was executed for the numerical example. We considered changes in two financial parameters and capacity of raw material production.

Twenty percent of change in budget parameter allocated to risk mitigation was taken into account. Table 13 shows these changes.

As it is observed, if we rise the budget, the NPV and Risk reduction objectives would improve, but LI objective has the best amount at $\$ 3,000,000$. Figures 3 and 4 demonstrate the amounts of variation in the values of objective functions in relation to the change in the parameter of budget and show the sensitivity of the problem. The sensitivity of the objective functions to change in the budget parameter shows a conflict between the objective functions.

Now, assuming that the allocated budget is $\$ 3,000,000$, the sensitivity of the model to the other parameters is measured. Table 13 reveals that the amount of lost sale is high. Investigation of results shows that the amount of LI is related to product 2, because while there are demands for this product, there is no production. If raw material suppliers increase the raw material capacity of product 2 , the

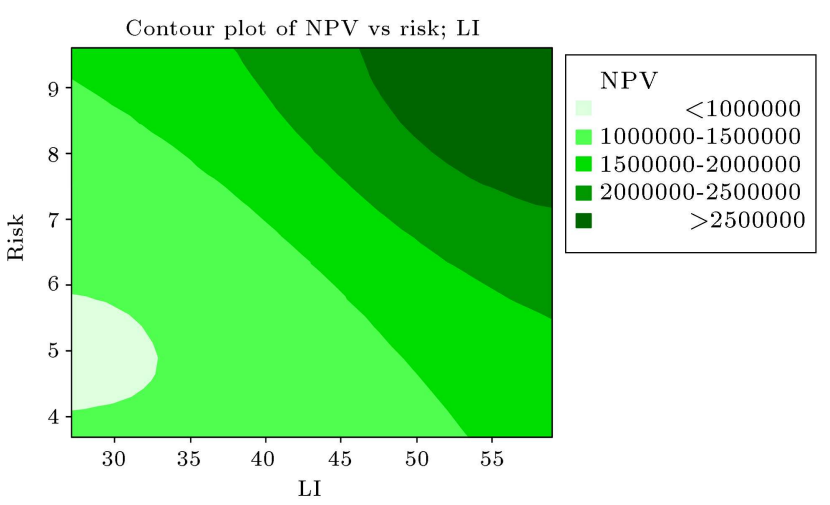

Figure 3. Pareto space contour chart.

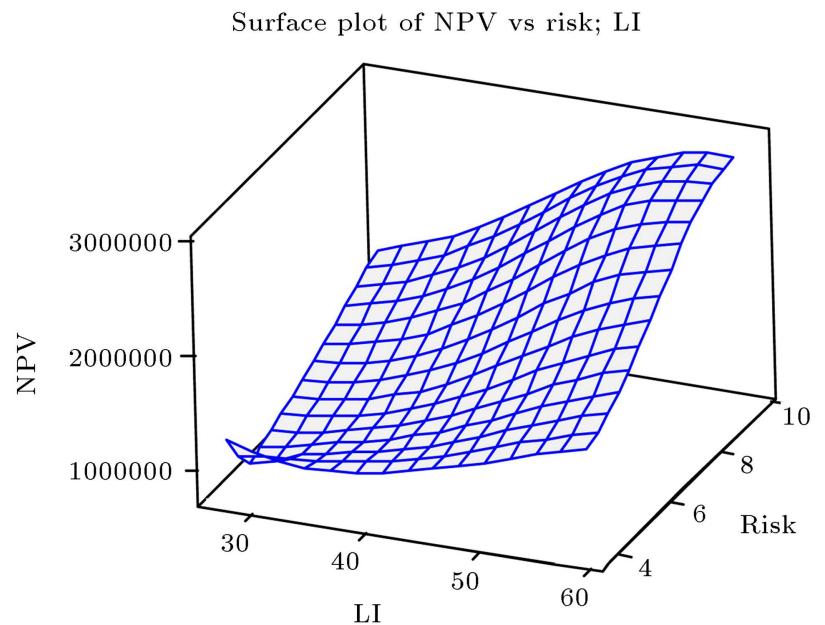

Figure 4. Pareto chart of budget changes.

LI objective function will be reduced. Therefore, in order to improve the LI objective function, capacity of suppliers needs to be increased or contracts with new suppliers must be closed. Table 14 shows these changes. 
Table 8. Transportation quantity of finished product $p$ from plant $l$ to demand region $r$.

\begin{tabular}{|c|c|c|c|c|c|}
\hline \multicolumn{3}{|c|}{$\boldsymbol{q}_{p,(l, r), t}^{\text {trans }}$} & \multirow[b]{2}{*}{$t_{1}$} & \multirow[b]{2}{*}{$t_{2}$} & \multirow[b]{2}{*}{$t_{3}$} \\
\hline Product $p$ & Manufacturer & Distributer & & & \\
\hline$p_{1}$ & $l_{1}$ & $r_{1}$ & $7.29 \mathrm{E}+03$ & 7790 & 6790 \\
\hline$p_{1}$ & $l_{1}$ & $r_{2}$ & 0 & & 30350 \\
\hline$p_{1}$ & $l_{1}$ & $r_{3}$ & 0 & 42265.00 & 0 \\
\hline$p_{1}$ & $l_{1}$ & $r_{4}$ & $1.04 \mathrm{E}+05$ & & 0 \\
\hline$p_{1}$ & $l_{1}$ & $r_{5}$ & 8460 & 19685.00 & 0 \\
\hline$p_{1}$ & $l_{1}$ & $r_{6}$ & 0 & 50260 & 28260 \\
\hline$p_{1}$ & $l_{2}$ & $r_{3}$ & 41820 & 42375.00 & 0 \\
\hline$p_{1}$ & $l_{2}$ & $r_{4}$ & 0 & 132625 & 0 \\
\hline$p_{1}$ & $l_{2}$ & $r_{5}$ & $1.22 \mathrm{E}+04$ & 0 & 0 \\
\hline$p_{1}$ & $l_{2}$ & $r_{6}$ & $5.23 \mathrm{E}+04$ & 0 & 25000 \\
\hline$p_{1}$ & $l_{3}$ & $r_{2}$ & 63700 & 0 & 0 \\
\hline$p_{1}$ & $l_{3}$ & $r_{3}$ & 0 & 0 & 0 \\
\hline$p_{1}$ & $l_{3}$ & $r_{4}$ & 0 & 85875 & 0 \\
\hline$p_{1}$ & $l_{3}$ & $r_{5}$ & 0 & 0 & 21685 \\
\hline$p_{2}$ & $l_{1}$ & $r_{6}$ & 0 & 0 & 0 \\
\hline$p_{2}$ & $l_{2}$ & $r_{1}$ & 5220 & 6220 & 5720 \\
\hline$p_{2}$ & $l_{2}$ & $r_{2}$ & 6455.333 & 9440 & 0 \\
\hline$p_{2}$ & $l_{2}$ & $r_{3}$ & 0 & 11910 & 0 \\
\hline$p_{2}$ & $l_{2}$ & $r_{4}$ & 0 & 0 & 16610 \\
\hline$p_{2}$ & $l_{2}$ & $r_{5}$ & 5175 & 5675 & 5275 \\
\hline$p_{2}$ & $l_{2}$ & $r_{6}$ & 0 & 5255 & 5455 \\
\hline$p_{2}$ & $l_{3}$ & $r_{1}$ & 0 & 0 & 0 \\
\hline$p_{2}$ & $l_{3}$ & $r_{2}$ & 0 & 0 & 10440 \\
\hline$p_{2}$ & $l_{3}$ & $r_{3}$ & 26649.67 & 0 & 0 \\
\hline$p_{2}$ & $l_{3}$ & $r_{4}$ & 0 & 5000 & 0 \\
\hline$p_{3}$ & $l_{1}$ & $r_{1}$ & 3135 & 0 & 0 \\
\hline$p_{3}$ & $l_{1}$ & $r_{2}$ & 0 & 12450 & 11950 \\
\hline$p_{3}$ & $l_{1}$ & $r_{3}$ & 0 & 0 & 0 \\
\hline$p_{3}$ & $l_{1}$ & $r_{4}$ & 51453 & 47828 & 35035 \\
\hline$p_{3}$ & $l_{1}$ & $r_{5}$ & 5190 & 0 & 0 \\
\hline$p_{3}$ & $l_{1}$ & $r_{6}$ & 6222 & 5722 & 0 \\
\hline$p_{3}$ & $l_{2}$ & $r_{1}$ & 0 & 2635 & 3235 \\
\hline$p_{3}$ & $l_{2}$ & $r_{2}$ & 12450 & 0 & 0 \\
\hline$p_{3}$ & $l_{2}$ & $r_{3}$ & 31200 & 31200 & 31400 \\
\hline$p_{3}$ & $l_{2}$ & $r_{4}$ & 0 & 0 & 36865 \\
\hline$p_{3}$ & $l_{2}$ & $r_{5}$ & 0 & 4690 & 0 \\
\hline$p_{3}$ & $l_{3}$ & $r_{4}$ & 21447 & 26072 & 0 \\
\hline$p_{3}$ & $l_{3}$ & $r_{5}$ & 0 & 0 & 5290 \\
\hline$p_{3}$ & $l_{3}$ & $r_{6}$ & 0 & 0 & 5922 \\
\hline$p_{4}$ & $l_{1}$ & $r_{1}$ & 1041 & 752 & \\
\hline$p_{4}$ & $l_{1}$ & $r_{2}$ & 5235 & 1735 & 5835 \\
\hline$p_{4}$ & $l_{1}$ & $r_{3}$ & 4170 & & 0 \\
\hline$p_{4}$ & $l_{1}$ & $r_{4}$ & 4440 & 10940 & 0 \\
\hline$p_{4}$ & $l_{1}$ & $r_{5}$ & 2091 & & 0 \\
\hline
\end{tabular}


Table 8. Transportation quantity of finished product $p$ from plant $l$ to demand region $r$ (continued).

\begin{tabular}{cccccc}
\hline & $\boldsymbol{q}_{\boldsymbol{p},(\boldsymbol{l}, \boldsymbol{r}), \boldsymbol{t}}^{\text {trans }}$ & & & & \\
\cline { 1 - 3 } Product $\boldsymbol{p}$ & Manufacturer & Distributer & $\boldsymbol{t}_{\mathbf{1}}$ & $\boldsymbol{t}_{\mathbf{2}}$ & $\boldsymbol{t}_{\mathbf{3}}$ \\
\hline$p_{4}$ & $l_{1}$ & $r_{6}$ & 0 & 5735 & 0 \\
$p_{4}$ & $l_{2}$ & $r_{1}$ & 0 & 139 & 0 \\
$p_{4}$ & $l_{2}$ & $r_{2}$ & 0 & 0 & 0 \\
$p_{4}$ & $l_{2}$ & $r_{3}$ & 0 & 4270 & 4370 \\
$p_{4}$ & $l_{2}$ & $r_{4}$ & 6000 & 0 & 0 \\
$p_{4}$ & $l_{2}$ & $r_{5}$ & 0 & 1591 & 0 \\
$p_{4}$ & $l_{2}$ & $r_{6}$ & 0 & 0 & 5335 \\
$p_{4}$ & $l_{3}$ & $r_{1}$ & 0 & 0 & 941 \\
$p_{4}$ & $l_{3}$ & $r_{2}$ & 0 & 3000 & 0 \\
$p_{4}$ & $l_{3}$ & $r_{4}$ & 0 & 0 & 12440 \\
$p_{4}$ & $l_{3}$ & $r_{5}$ & 0 & 0 & 1791 \\
$p_{4}$ & $l_{3}$ & $r_{6}$ & 5235 & 0 & 0 \\
\hline
\end{tabular}

Table 9. Transportation quantity of raw material $k$ on transportation connection from supplier $s$ to plant $l$.

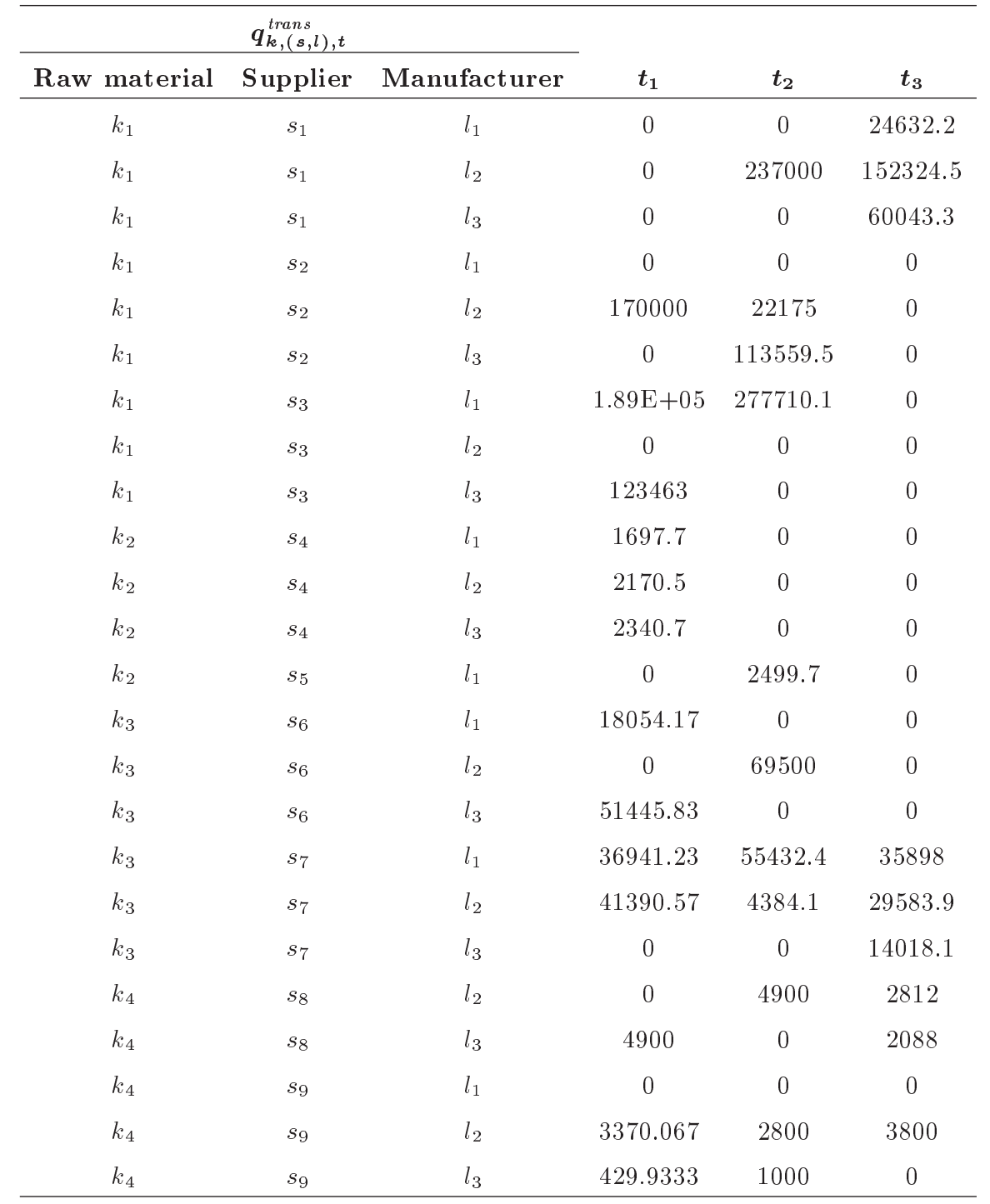


Table 10. Raw material quantity supplied by supplier and production quantity of the finished product.

\begin{tabular}{|c|c|c|c|c|c|c|c|c|c|}
\hline \multicolumn{2}{|c|}{$\boldsymbol{q}_{k, s, t}^{r a w}$} & \multirow[b]{2}{*}{$t_{1}$} & \multirow[b]{2}{*}{$t_{2}$} & \multirow[b]{2}{*}{$t_{3}$} & \multicolumn{2}{|r|}{$\boldsymbol{q}_{p, l, t}^{\text {conv }}$} & \multirow[b]{2}{*}{$t_{1}$} & \multirow[b]{2}{*}{$t_{2}$} & \multirow[b]{2}{*}{$t_{3}$} \\
\hline $\begin{array}{c}\text { Raw } \\
\text { material }\end{array}$ & Supplier & & & & Product & Manufacturer & & & \\
\hline$k_{1}$ & $s_{1}$ & 0 & 237000 & 237000 & $p_{1}$ & $l_{1}$ & 105250 & 32650 & 103840 \\
\hline$k_{1}$ & $s_{2}$ & 170000 & 135734.5 & 0 & $p_{1}$ & $l_{2}$ & 103165 & 175000 & 127135 \\
\hline$k_{1}$ & $s_{3}$ & 312742.3 & 277710.1 & 0 & $p_{1}$ & $l_{3}$ & 70465 & 42220 & 30650 \\
\hline$k_{2}$ & $s_{4}$ & 6208.9 & 0 & 0 & $p_{2}$ & $l_{2}$ & 38275 & 15810 & 27635 \\
\hline$k_{2}$ & $s_{5}$ & 0 & 2499.7 & 0 & $p_{2}$ & $l_{3}$ & 5225 & 27690 & 15865 \\
\hline$k_{3}$ & $s_{6}$ & 69500 & 69500 & 0 & $p_{3}$ & $l_{1}$ & 39905 & 55357 & 54457 \\
\hline$k_{3}$ & $s_{7}$ & 78331.8 & 59816.5 & 79500 & $p_{3}$ & $l_{2}$ & 71500 & 71500 & 71500 \\
\hline$k_{4}$ & $s_{8}$ & 4900 & 4900 & 4900 & $p_{3}$ & $l_{3}$ & 20952 & 5000 & 5000 \\
\hline \multirow[t]{3}{*}{$k_{4}$} & $s_{9}$ & 3800 & 3800 & 3800 & $p_{4}$ & $l_{1}$ & 7540 & 12135 & 5000 \\
\hline & & & & & $p_{4}$ & $l_{2}$ & 25239 & 6000 & 22982 \\
\hline & & & & & $p_{4}$ & $l_{3}$ & 3000 & 3000 & 3000 \\
\hline
\end{tabular}

Table 11. Quantity of lost order of finished product $p$ in demand region.

\begin{tabular}{|c|c|c|c|c|}
\hline \multicolumn{2}{|c|}{$\boldsymbol{q}_{p, r, t}^{\text {lost }}$} & \multirow[b]{2}{*}{$t_{1}$} & \multirow[b]{2}{*}{$t_{2}$} & \multirow[b]{2}{*}{$t_{3}$} \\
\hline $\begin{array}{l}\text { Finished } \\
\text { product }\end{array}$ & Distributer & & & \\
\hline$p_{2}$ & $r_{3}$ & 15410 & 15910 & 9695 \\
\hline$p_{2}$ & $r_{4}$ & 73600 & 75600 & 74600 \\
\hline$p_{2}$ & $r_{6}$ & 0 & 0 & 5515 \\
\hline
\end{tabular}

Table 12. Optimal values of objective functions.

\begin{tabular}{ll}
\hline Objective function & Optimum \\
\hline NPV & 7976866.78 \\
Risk & 5.974 \\
LI & 2666954.4 \\
& \\
& $w_{N P D}=0.8$ \\
Weight of objective & $w_{\text {risk }}=0.048$ \\
& $w_{L I}=0.472$ \\
\hline
\end{tabular}

Convention cost is changed in order to analyze the impacts of cost efficiency differences between production plants. Table 15 investigates the impact of changes in production costs on products 2 and 4 (new product). The production cost for product 2 is reduced by $20 \%$ and, in the next row, the production cost for product 4 in the three plants increases by $20 \%$.

In Table 16, the changes in two parameters of pro- duction cost for product 2 and production capacity of raw material are simultaneously investigated. We aim to concurrently estimate the decrease in the amount of LI with these changes. Production costs drop by $20 \%$ and production capacity is doubled for the first and third raw materials and tripled for the fourth raw material.

As it is represented in Table 16, the NPV and LI objective functions have been significantly improved. These changes will result in an increase by $12.9 \%$ in NPV, a decrease by $78.8 \%$ in the LI objective function, and a decrease by $7.2 \%$ in the amount of risk objective function.

The changes of parameters and the observed results prove efficacy of the model and it can be concluded that the model is flexible enough.

\subsection{More cases}

To test the efficiency and robustness of the optimization procedure, more cases by multiplying some of the parameters are provided. Table 17 shows the results.

As it can be observed, by multiplying the parameters of the problem, the time of solving increases and the model will not be solved within a reasonable time. Meta heuristic algorithms can be used for solving such large-scale problems.

\section{Conclusion and future work}

New Product Development (NPD) works as a key for companies in different industries like Fast Moving Consumer Goods (FMCG) to succeed in the competitive market. On the other hand, developing a new product poses various risks to companies. The ability 
Table 13. Changes in the budget allocated to risk mitigation.

\begin{tabular}{|c|c|c|c|c|c|c|c|c|c|}
\hline $\begin{array}{l}\text { Budget } \\
\text { quantity }\end{array}$ & $\begin{array}{l}\text { NPV objective } \\
\text { (percentage of } \\
\text { changes in } \\
\text { NPV objective) }\end{array}$ & $\begin{array}{c}\text { Risk } \\
\text { objective }\end{array}$ & $\begin{array}{c}\text { LI } \\
\text { objective }\end{array}$ & $\begin{array}{l}\text { Risk response strategies } \\
\text { that are not selected } \\
\text { (number of risks selected) }\end{array}$ & $\begin{array}{r}\text { Produ } \\
\text { product } \\
\left(p_{4} \text { is } 1\right.\end{array}$ & $p_{i}$ & $\begin{array}{l}\text { g fi } \\
\text { in } \\
\text { pr }\end{array}$ & c & $\begin{array}{l}\text { hed } \\
\text { unt } L_{l}\end{array}$ \\
\hline \multirow{5}{*}{$\$ 2,400,000$} & \multirow{5}{*}{$\begin{array}{l}7,807,999.036 \\
(-\% 2)\end{array}$} & \multirow{5}{*}{4.91} & \multirow{5}{*}{$2,776,186.8$} & \multirow{5}{*}{$\begin{array}{c}q_{2}, q_{4}, q_{6}, q_{7}, q_{9}, q_{11,}, q_{13}, q_{16}, q_{17} \\
(11)\end{array}$} & & $L_{1}$ & $L_{2}$ & $L$ & \\
\hline & & & & & $p_{1}$ & $\bullet$ & $\bullet$ & $\bullet$ & \\
\hline & & & & & $p_{2}$ & • & - & $\bullet$ & \\
\hline & & & & & $p_{3}$ & $\bullet$ & $\bullet$ & $\bullet$ & \\
\hline & & & & & $p_{4}$ & $\bullet$ & $\bullet$ & $\bullet$ & \\
\hline \multirow{5}{*}{$\$ 3,000,000$} & \multirow{5}{*}{$\begin{array}{c}7,976,866.78 \\
(\% 0)\end{array}$} & \multirow{5}{*}{5.97} & \multirow{5}{*}{$2,666,954.4$} & \multirow{5}{*}{$\begin{array}{c}q_{4}, q_{6}, q_{7}, q_{9}, q_{15}, q_{16} \\
(14)\end{array}$} & & $L_{1}$ & $L_{2}$ & $L$ & \\
\hline & & & & & $p_{1}$ & $\bullet$ & $\bullet$ & $\bullet$ & \\
\hline & & & & & $p_{2}$ & - & • & $\bullet$ & \\
\hline & & & & & $p_{3}$ & $\bullet$ & $\bullet$ & $\bullet$ & \\
\hline & & & & & $p_{4}$ & $\bullet$ & $\bullet$ & $\bullet$ & \\
\hline \multirow{5}{*}{$\$ 3,600,000$} & \multirow{5}{*}{$\begin{array}{l}7,993,532.23 \\
(+\% 0.2)\end{array}$} & \multirow{5}{*}{6.73} & \multirow{5}{*}{$2,735,622.24$} & \multirow{5}{*}{$\begin{array}{l}q_{4}, q_{7}, q_{15} \\
\quad(17)\end{array}$} & & $L_{1}$ & $L_{2}$ & $L_{3}$ & \\
\hline & & & & & $p_{1}$ & $\bullet$ & $\bullet$ & $\bullet$ & \\
\hline & & & & & $p_{2}$ & - & $\bullet$ & 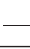 & \\
\hline & & & & & $p_{3}$ & $\bullet$ & - & $\bullet$ & \\
\hline & & & & & $p_{4}$ & $\bullet$ & • & $\bullet$ & \\
\hline
\end{tabular}

Table 14. Effect of changes in raw material capacity on the results.

\begin{tabular}{|c|c|c|c|c|c|c|c|c|c|c|c|c|}
\hline $\begin{array}{l}\text { Amount of increase } \\
\text { in raw material } \\
\text { production capacity }\end{array}$ & $\begin{array}{c}\text { NPV objective } \\
\text { (percentage of } \\
\text { changes in NPD } \\
\text { objective) }\end{array}$ & $\begin{array}{c}\text { Risk } \\
\text { objective }\end{array}$ & $\begin{array}{c}\text { LI } \\
\text { objective }\end{array}$ & $\begin{array}{r}\operatorname{Pr} \\
\mathrm{f} \\
\mathrm{pr} \\
\text { in } \\
(p \\
\mathrm{p}\end{array}$ & $\begin{array}{l}\text { odv } \\
\text { pla } \\
4 \text { is } \\
\text { rod }\end{array}$ & $\begin{array}{l}\text { ict } \\
\text { nt } \\
\text { ne } \\
\text { luct }\end{array}$ & & & $\begin{array}{l}\text { lo } \\
\text { ir }\end{array}$ & $\begin{array}{l}\text { iished } \\
\text { st sal } \\
\text { distri } \\
\text { each }\end{array}$ & $\begin{array}{l}\text { prod } \\
\text { es in } s \\
\text { buters } \\
\text { perio }\end{array}$ & $\begin{array}{l}\text { luct } \\
\text { six } \\
\text { s } \\
\text { od }\end{array}$ \\
\hline \multirow{5}{*}{$\begin{array}{l}\text { Production capacity } \\
\text { of the raw material } \\
\text { for } 1,3 \text {, and } 4 \text { doubles }\end{array}$} & \multirow{5}{*}{$\begin{array}{c}8,523,305.015 \\
(+\% 6.8)\end{array}$} & \multirow{5}{*}{5.97} & \multirow{5}{*}{$1,626,847.2$} & \multicolumn{2}{|c|}{$L_{1}$} & \multirow{2}{*}{\begin{tabular}{|c|}
$L_{2}$ \\
$\bullet$
\end{tabular}} & \multirow{2}{*}{$L_{3}$} & \multirow[b]{2}{*}{$p_{1}$} & \multirow{2}{*}{\multicolumn{2}{|c|}{$\frac{\boldsymbol{t}_{\mathbf{1}}}{0}$}} & \multirow{2}{*}{$\frac{t_{2}}{0}$} & $t_{3}$ \\
\hline & & & & $p_{1}$ & $\begin{array}{ll} \\
\end{array}$ & & & & & & & 0 \\
\hline & & & & $p_{2}$ & • & • & • & $p_{2}$ & $r_{4}$ & 54010 & 56510 & 54810 \\
\hline & & & & $p_{3}$ & • & • & $\bullet$ & $p_{3}$ & $\vdots$ & 0 & 0 & 0 \\
\hline & & & & $p_{4}$ & $\bullet$ & $\bullet$ & $\bullet$ & $p_{4}$ & $\vdots$ & 0 & 0 & 0 \\
\hline
\end{tabular}

to respond to and mitigate those risk events puts a company ahead of its rivals and reduces the expected long-term damage to its business. Given these tips, this paper aimed to identify a new model for a multiechelon, multi-product, multi-source, and multi-period optimization model for Supply Chain (SC) configuration and NPD with risk management. To determine the adequate $\mathrm{SC}$ configuration, three levels of decision should be made, namely strategic, tactical, and operational, to optimize the expected profit, level of risk, and consumer satisfaction based on the classifications discussed in $[20,10,7]$. The strategic decisions involved the quantity and place of distribution centers for distributing new products. The tactical decisions were production rate of each selected factory to produce a new product in addition to the old ones and the 
Table 15. Changes in conversion cost of final products 2 and 4.

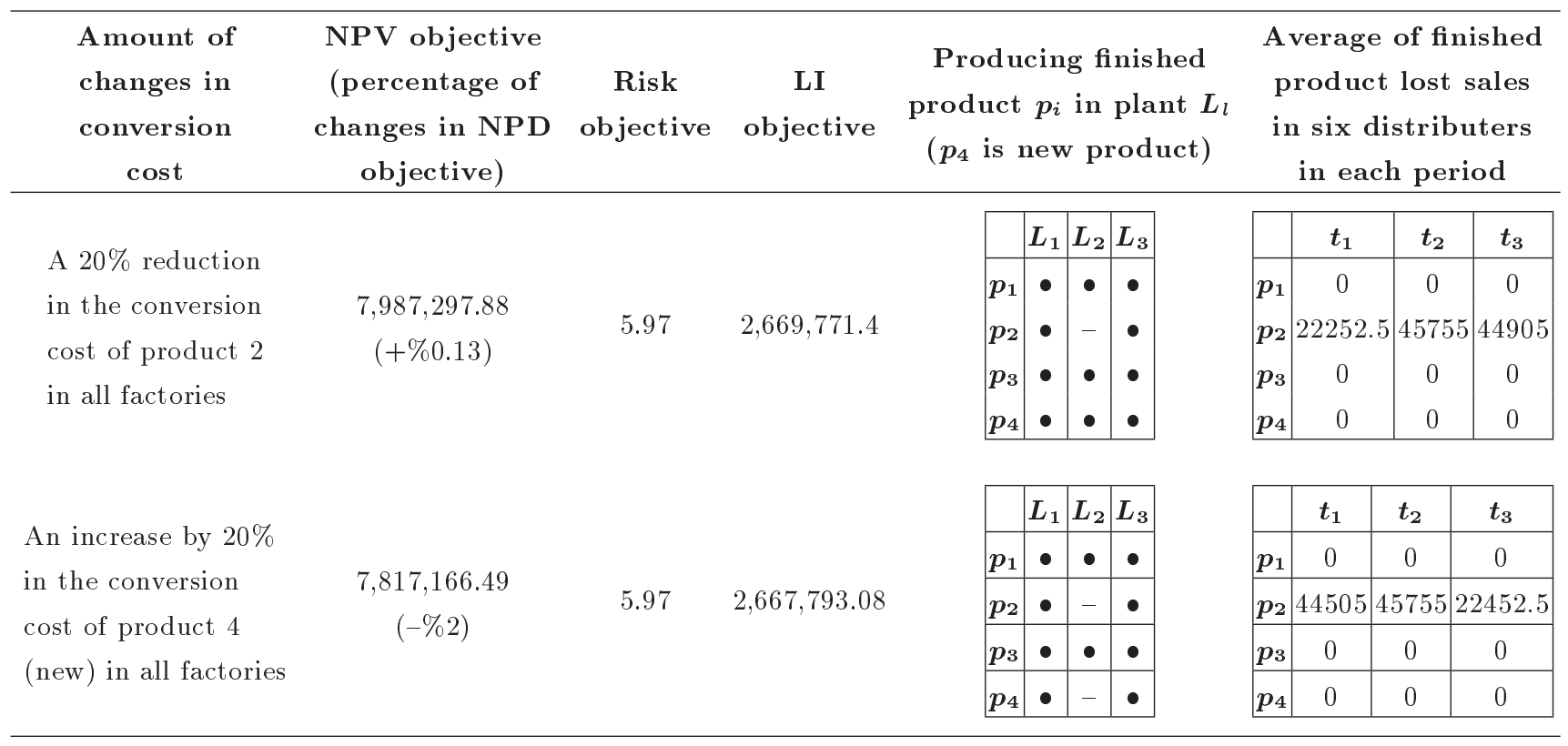

Table 16. Effect of changes in production cost and raw material capacity on the results.

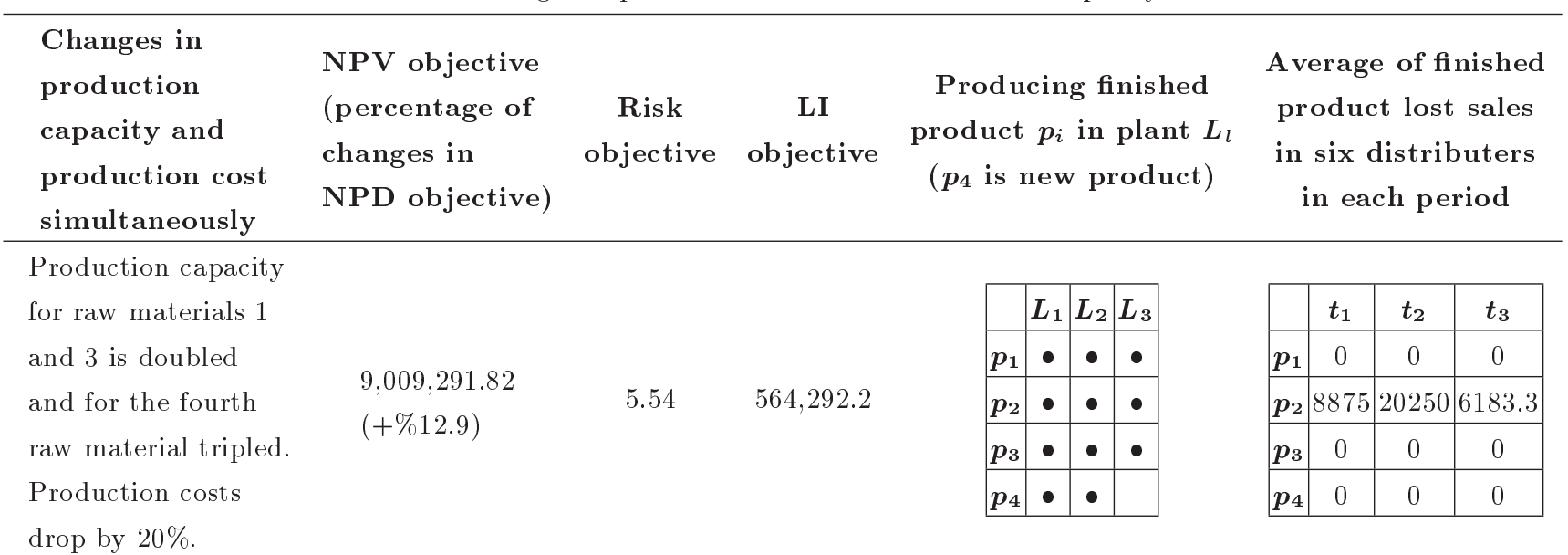

Table 17. Another case with larger dimensions.

\begin{tabular}{|c|c|c|c|c|c|c|c|c|c|c|}
\hline \multirow{2}{*}{ Case } & \multicolumn{3}{|c|}{ Number of } & \multicolumn{2}{|c|}{ Number of } & \multicolumn{3}{|c|}{ Objectives } & \multirow{2}{*}{$\begin{array}{c}\text { Goal } \\
\text { programming } \\
\text { Objective }\end{array}$} & \multirow{2}{*}{ Time (s) } \\
\hline & Suppliers & Plants & Distributers & $\begin{array}{c}\text { Raw } \\
\text { materials }\end{array}$ & $\begin{array}{l}\text { Finished } \\
\text { products }\end{array}$ & NPV (\$) & Risk & LI (\$) & & \\
\hline 1 & 9 & 3 & 6 & 4 & 4 & $1.565 * 10^{6}$ & 10.114 & $1.974 * 10^{5}$ & 0.820 & 5.95 \\
\hline 2 & 36 & 12 & 12 & 4 & 8 & $4.356 * 10^{7}$ & 10.199 & $1.141 * 10^{7}$ & 0.851 & 127.65 \\
\hline 3 & 144 & 48 & 24 & 4 & 16 & $2.604 * 10^{8}$ & 20.167 & $3.026 * 10^{8}$ & 0.95 & 1705.9 \\
\hline
\end{tabular}

appropriate risk response strategies. The operational decisions were the transportation quantity of new and present products in the new network and the essential inventory levels in each factory and distribution center. Tactical as well as operational decisions-i.e. how much to source, produce, and sell-had to be made upon the product-plant allocation and decisions on choosing the best mitigating risk response strategies were made by running the model. The impact of each risk response strategy on capacity of suppliers, factories, and demand was included in the model. It was solved by GAMS software. 
Sensitivity analysis showed the impact of some different parameters on the objectives. It showed significant improvement in all objective functions by increasing raw material capacity of suppliers and decreasing production costs. By increasing the budget allocated to risk mitigation, an improvement in NPV and Risk objectives was observed, but the Lost Income (LI) increased. This occurred because when the budget increased, the quantity of mitigation strategies rose from 11 to 17 . That is, adopting some risk response strategies related to increase in demand raised LI.

The model is capable to reconfigure an SC in the presence a new product. For future research, taking a solution approach for large-scale instances of the proposed model can be of significance. As another suggestion, the problem can be investigated with stochastic parameters such as demand, cycle times, and price.

\section{References}

1. Ramezani, M., Kimiagari, A.M., and Karimi, B. "Interrelating physical and financial flows in a biobjective closed-loop supply chain network problem with uncertainty", Scientia Iranica, Transaction E, Industrial Engineering, 22(3), pp. 1278-1293 (2015).

2. Afshar-Bakeshloo, M., Bozorgi-Amiri, A., Sajadi, S.M., and Jolai, F. "A multi-objective environmental Hedging point policy with customer satisfaction criteria", Journal of Cleaner Production, 179, pp. 478-494 (2018).

3. Markham, S.K. and Lee, H. "Product development and management association's 2012 comparative performance assessment study", Journal of Product Innovation Management, 30(3), pp. 408-429 (2013).

4. Brandenburg, M. "A hybrid approach to configure ecoefficient supply chains under consideration of performance and risk aspects", Omega, 70, pp. 58-76 (2017).

5. Mu, J., Peng, G., and MacLachlan, D.L. "Effect of risk management strategy on NPD performance", Technovation, 29(3), pp. 170-180 (2009).

6. Aqlan, F. and Lam, S.S. "Supply chain optimization under risk and uncertainty: A case study for highend server manufacturing", Computers \& Industrial Engineering, 93, pp. 78-87 (2016).

7. Qazi, A., Quigley, J., and Dickson, A. "Supply chain risk management: Systematic literature review and a conceptual framework for capturing interdependencies between risks", Industrial Engineering and Operations Management (IEOM), 2015 International Conference on. IEEE, pp. 1-13 (2015).

8. Liu, B. and Sun, F. "Research on the risk assessment method of PPP project based on the improved matter element model", Scientia Iranica, 27(2), pp. 614-624 (2020).
9. Fourt, L.A. and Woodlock, J.W. "Early prediction of market success for new grocery products", The Journal of Marketing, 25(2), pp. 31-38 (1960).

10. Amini, M. and Li, H. "Supply chain configuration for diffusion of new products: an integrated optimization approach", Omega, 39(3), pp. 313-322 (2011).

11. Li, H. and Amini, M. "A hybrid optimisation approach to configure a supply chain for new product diffusion: a case study of multiple-sourcing strategy", International Journal of Production Research, 50(11), pp. 3152-3171 (2012).

12. Gaur, J., Amini, M., and Rao, A.K. "Closed-loop supply chain configuration for new and reconditioned products: An integrated optimization model", Omega, 66, pp. 212-223 (2017).

13. Nepal, B., Monplaisir, L., and Famuyiwa, O. "A multi-objective supply chain configuration model for new products", International Journal of Production Research, 49(23), pp. 7107-7134 (2011).

14. Jafarian, M. and Bashiri, M. "Supply chain dynamic configuration as a result of new product development", Applied Mathematical Modelling, 38(3), pp. 1133-1146 (2014).

15. Alizadeh Afrouzy, Z., Nasseri, S.H., and Mahdavi, I. "A genetic algorithm for supply chain configuration with new product development", Computers \& Industrial Engineering, 101, pp. 440-454 (2016).

16. Alizadeh Afrouzy, Z., Nasseri, S.H., Mahdavi, I., and Paydar, M.M. "A fuzzy stochastic multi-objective optimization model to configure a supply chain considering new product development", Applied Mathematical Modelling, 40(17-18), pp. 7545-7570 (2016).

17. Brandenburg, M. "Low carbon supply chain configuration for a new product-a goal programming approach", International Journal of Production Research, 53(21), pp. 6588-6610 (2015).

18. Graves, S.C. and Willems, S.P. "Optimizing the supply chain configuration for new products", Management Science, 51(8), pp. 1165-1180 (2005).

19. Chauhan, S.S., Nagi, R., and Proth, J.-M. "Strategic capacity planning in supply chain design for a new market opportunity", International Journal of Production Research, 42(11), pp. 2197-2206 (2004).

20. Jahani, H., Abbasi, B., and Alavifard, F. "Supply chain network reconfiguration in new products launching phase", Industrial Engineering and Engineering Management (IEEM), 2017 IEEE International Conference on. IEEE, pp. 95-99 (2017).

21. Klibi, W., Martel, A., and Guitouni, A. "The design of robust value-creating supply chain networks: a critical 
review", European Journal of Operational Research, 203(2), pp. 283-293 (2010).

22. Kayis, B., Arndt, G., Zhou, M., and Amornsawadwatana, S. "A risk mitigation methodology for new product and process design in concurrent engineering projects", CIRP Annals-Manufacturing Technology, 56(1), pp. 167-170 (2007).

23. Tang, O. and Nurmaya Musa, S. "Identifying risk issues and research advancements in supply chain risk management", International Journal of Production Economics, 133(1), pp. 25-34 (2011).

24. Prakash, S., Soni, G., and Rathore, A.P.S. "A critical analysis of supply chain risk management content: a structured literature review", Journal of Advances in Management Research, 14(1), pp. 69-90 (2017).

25. Peidro, D., Mula, J., Poler, R., and Lario, F.C. "Quantitative models for supply chain planning under uncertainty: a review", The International Journal of Advanced Manufacturing Technology, 43(3-4), pp. 400-420 (2009).

26. Khojasteh-Ghamari, Z. and Irohara, T. "Supply chain risk management: A comprehensive review", Supply Chain Risk Management, Springer, Singapore, pp. 322 (2018).

27. Sahling, F. and Kayser, A. "Strategic supply network planning with vendor selection under consideration of risk and demand uncertainty", Omega, 59, pp. 201214 (2016).

28. Guillén, G., Mele, F.D., Bagajewicz, M.J., Espuna, A., and Puigjaner, L. "Multiobjective supply chain design under uncertainty", Chemical Engineering Science, 60(6), pp. 1535-1553 (2005).

29. Azaron, A., Brown, K.N., Tarim, S.A., and Modarres, M. "A multi-objective stochastic programming approach for supply chain design considering risk", International Journal of Production Economics, 116(1), pp. $129-138$ (2008).

30. Nickel, S., Saldanha-da-Gama, F., and Ziegler, H.-P. "A multi-stage stochastic supply network design problem with financial decisions and risk management", Omega, 40(5), pp. 511-524 (2012).

31. Huang, G.Q., Zhang, X.Y., and Liang, L. "Towards integrated optimal configuration of platform products, manufacturing processes, and supply chains", Journal of Operations Management, 23(3-4), pp. 267-290 (2005).

32. Heckmann, I., Comes, T., and Nickel, S. "A critical review on supply chain risk-definition, measure and modeling", Omega, 52, pp. 119-132 (2015).

33. Fahimnia, B., Tang, C.S., Davarzani, H., and Sarkis, J. "Quantitative models for managing supply chain risks:
A review", European Journal of Operational Research, 24(1), pp. 1-15 (2015).

34. Brandenburg, M. and Schilling, R. "Value impacts of dynamics and uncertainty in tactical supply chain design for new product introduction", Proceedings of the German-Italian Conference on the Interdependencies Between New Product Development and Supply Chain Management, pp. 26-39 (2010).

35. Brandenburg, M., Kuhn, H., Schilling, R., and Seuring, S. "Performance-and value-oriented decision support for supply chain configuration", Logistics Research, 7(1), p. 118 (2014).

36. Butler, R.J., Ammons, J.C., and Sokol, J. "Planning the supply chain network for new products: A case study", Engineering Management Journal, 18(2), pp. $35-43$ (2006).

37. Hansen, K.R.N. and Grunow, M. "Planning operations before market launch for balancing time-to-market and risks in pharmaceutical supply chains", International Journal of Production Economics, 161, pp. 129-139 (2015).

38. Higuchi, T. and Troutt, M.D. "Dynamic simulation of the supply chain for a short life cycle product-lessons from the Tamagotchi case", Computers \& Operations Research, 31(7), pp. 1097-1114 (2004).

39. Pan, F. and Nagi, R. "Robust supply chain design under uncertain demand in agile manufacturing", Computers \& Operations Research, 37(4), pp. 668-683 (2010).

40. Schilling, R., Brandenburg, M., and Kuhn, H. "Simulation-based evaluation of tactical supply chain design scenarios for new product introduction", International Annual EurOMA Conference : Managing Operations in Service Economics (2010).

41. Farahani, R.Z., Rezapour, S., Drezner, T., and Fallah, S. "Competitive supply chain network design: An overview of classifications, models, solution techniques and applications", Omega, 45, pp. 92-118 (2014).

\section{Biographies}

Malihe Sabzevari is currently a $\mathrm{PhD}$ candidate in the College of Industrial Engineering at Iran University of Science and Research in Tehran. She obtained her MSc degree in Industrial Engineering from Science and Research Branch of Islamic Azad University, Iran, in 2011 and her BSc degree in Mathematics from Alzahra University, Iran, in 2006. Her research interests are operations research, supply chain management, and stock market.

Seyed Mojtaba Sajadi received his $\mathrm{PhD}$ degree in Industrial Engineering from Amirkabir University of Technology, Tehran, Iran, in 2010. He is currently an Associate Professor in the Faculty of Entrepreneurship at University of Tehran. His research interests 
are operations research, control of large production and inventory systems, simulation-based optimization methods, statistical process, design of experiments, entrepreneurial supply chain management, and metaheuristic algorithms.

Seyed Mohammad Hadjimolana graduated with
BSc from Sharif University of Technology and with MSC and PhD from Amirkabir University of Technology in Iran. He is the head of Industrial Engineering Department at Science and Research Branch of Islamic Azad University. His research interests are supply chain management, advanced inventory control, and production planning. 